\title{
Alüminyum Alaşımı Yüzeyine Kaplanan Tabakaların Mikroyapı ve Yüzey Pürüzlülüğünün İncelenmesi
}

\author{
Serkan ÖZEL*, Erdinç VURAL \\ Bitlis Eren Üniversitesi, Mühendislik Mimarlık Fakültesi, Bitlis, Türkiye
}

\begin{abstract}
Özet
$\mathrm{Bu}$ çalışmada, alüminyum alaşımı yüzeyine, $\mathrm{Al}_{2} \mathrm{O}_{3}+\% 13 \mathrm{TiO}_{2}, \mathrm{Cr}_{2} \mathrm{O}_{3}$ ve $\mathrm{Cr}_{2} \mathrm{O}_{3}+\% 25 \mathrm{Al}_{2} \mathrm{O}_{3}$ tozları plazma püskürtme tekniği kullanılarak kaplanmıştır. Kaplama tabakalarının optik mikroskopta mikroyapı resimleri çekilmiş ve yüzey pürüzlülük değerleri ölçülmüştür. Deney sonuçları incelendiğinde, plazma püskürtme yöntemi ile gerçekleştirilen kaplamalarda, kaplama tabakasında gözenekli bir yapının oluştuğu görülmüştür. En düşük gözeneklilik miktarı $\mathrm{Cr}_{2} \mathrm{O}_{3}$ tozu ile kaplanan numunede görülmüştür. En düşük yüzey pürüzlülüğü ise $\mathrm{Cr}_{2} \mathrm{O}_{3}+\% 25 \mathrm{Al}_{2} \mathrm{O}_{3}$ tozu ile kaplanan numunede ölçülmüştür.
\end{abstract}

Anahtar Kelimeler: Plazma püskürtme, kaplama, yüzey pürüzlülüğü

\section{The Investigation of Microstructure and Surface Roughness of Layers Coated Aluminum Alloy Surface}

\begin{abstract}
In this study, the surface of an aluminium alloy has been coated with $\mathrm{Al}_{2} \mathrm{O}_{3}+13 \% \mathrm{TiO}_{2}, \mathrm{Cr}_{2} \mathrm{O}_{3}$ and $\mathrm{Cr}_{2} \mathrm{O}_{3}+25 \% \mathrm{Al}_{2} \mathrm{O}_{3}$ powder using plasma spraying technique. The microstructure pictures of the coating layers have been taken and a surface roughness of the coating layers has been measured. When the result of the experiment was analyzed, it has been observed that a porous structure has been formed on the coating layers. The lowest porosity was observed in the $\mathrm{Cr}_{2} \mathrm{O}_{3}$ coating. However, the minimum surface roughness was observed in the $\mathrm{Cr}_{2} \mathrm{O}_{3}+25 \% \mathrm{Al}_{2} \mathrm{O}_{3}$ coating.
\end{abstract}

Keywords: Plasma spray, coating, surface roughness

\section{Giriş}

Is1l püskürtme yöntemi yüzeylerin aşınma ve korozyona karşı korunmasında endüstride geniş bir kullanım alanına sahip bir işlemdir [1]. Son 20 yılda kullanılan tekniklere nazaran daha yeni bir kaplama yöntemidir. Bu yöntemin en geniş kullanım alanı, makine parçaları ve otomotiv endüstrisidir. Yöntem, süper alaşımların özel kaplamalarında ve gaz tribün mühendisliğinde kullanılmaktadır [2, 3]. Kaplama malzemesinin ergitilerek daha önceden pürüzlendirilmiş ana malzeme (altlık) üzerine püskürtülmesi esasına dayanan 1sıl püskürtme sistemleri, kullanılan enerji kaynağı (yanıcı gaz veya elektrik), kaplama malzemesi formu (tel, toz veya çubuk), ve atmosfer (hava, düşük basınç veya soy gaz) bakımından birbirinden farklılık gösterir $[4,5]$.

Plazma püskürtme kaplama yöntemi, metallerin çeşitli tozlarla kaplanarak aşınmaya, oksitlenmeye, korozyona ve 1sıya dayanıklı hale getirilmesinde yaygın olarak kullanılan bir 1sıl püskürtme kaplama yöntemidir. Bu yöntemle gerçekleştirilen ince bir kaplama sayesinde belirtilen özellikler elde edildiği gibi, ana malzemenin üstün özelliklerinden tokluk ve kolay şekillendirilebilme özellikleri de korunmaktadır. Böylece plazma püskürtme kaplama, metal ve seramiklerin üstün

*Sorumlu Yazar: sozel@beu.edu.tr 
özelliklerinin yeni bir malzemede toplanmasına imkân sağlamaktadır. Plazma püskürtme yöntemiyle gerçekleştirilen seramik kaplamalar birçok metalden daha iyi aşınma ve erozyon direncine sahiptirler ve dizel motorları da dâhil erozyon ve aşınma dirençli uygulamalarda yaygın olarak kullanılırlar [6].

$\mathrm{Al}_{2} \mathrm{O}_{3}, \mathrm{Cr}_{2} \mathrm{O}_{3}, \mathrm{ZrO}_{2}, \mathrm{TiO}_{2}$ gibi seramik malzemeler, yüksek mukavemet, iyi tribolojik ve korozyon performansı ve düşük termal iletkenliklerinden dolayı malzeme yüzeylerinde koruyucu kaplama olarak kullanılmaktadır. $\mathrm{Al}_{2} \mathrm{O}_{3}$ esaslı seramik kaplamalar, aşınma, erozyon, termal şok ve korozyon direnci gibi özelliklerin istendiği yerlerde kullanılmaktadır. $\mathrm{Al}_{2} \mathrm{O}_{3}$ içerisine $\mathrm{TiO}_{2}$ eklenmesi, $\mathrm{Al}_{2} \mathrm{O}_{3}$ kaplamaların özelliklerini arttırır [7]. $\mathrm{Al}_{2} \mathrm{O}_{3}+\% 13 \quad \mathrm{TiO}_{2}$ kaplamalar $\mathrm{Al}_{2} \mathrm{O}_{3}-\mathrm{TiO}_{2}$ kaplamalar arasında yüksek aşınma direnci gösteren karışımlardandır [8]. $\mathrm{Cr}_{2} \mathrm{O}_{3}-\mathrm{Al}_{2} \mathrm{O}_{3}$ kompozit kaplamalar, genellikle gemi ve uçak parçalarının sürtünmeli çalışan kısımlarının yüksek aşınma ve sıcaklık koşulları altında çalıştığı yerlerde kullanılmaktadır [9].

$\mathrm{Bu}$ çalışmada, alüminyum alaşımı yüzeyine, $\mathrm{Al}_{2} \mathrm{O}_{3}+\% 13 \mathrm{TiO}_{2}, \mathrm{Cr}_{2} \mathrm{O}_{3}$ ve $\mathrm{Cr}_{2} \mathrm{O}_{3}+\% 25 \mathrm{Al}_{2} \mathrm{O}_{3}$ tozları plazma püskürtme tekniği kullanılarak kaplanmıştır. Kaplama tabakalarının optik mikroskopta mikroyapı resimleri ve yüzey pürüzlülük değerleri incelenmiştir.

\section{Materyal ve Yöntem}

Alt malzeme olarak seçilen alüminyum alaşımı, piston malzemesi olarak kullanılan alüminyum alaşımıdır. Bu alaşımın \% ağırlıkça kimyasal bileşimi Tablo 1'de verilmiştir. Numuneler, yüzey pürüzlülüğünün sağlanması amac1 ile 60 PSI'lik basınç altında $\mathrm{Al}_{2} \mathrm{O}_{3}$ kullanılarak yüzey pürüzlendirme işlemine tabi tutulmuştur. Yüzey pürüzlendirme işlemine tabi tutulan numunelerin yüzeylerine, $\mathrm{Al}_{2} \mathrm{O}_{3}+\% 13 \mathrm{TiO}_{2}, \mathrm{Cr}_{2} \mathrm{O}_{3}$ ve $\mathrm{Cr}_{2} \mathrm{O}_{3}+\% 25 \mathrm{Al}_{2} \mathrm{O}_{3}$ tozlar1 plazma püskürtme tekniği kullanılarak kaplanmıştır. Plazma püskürtme kaplama işlemleri Şekil 1'de verilen şematik resimde şekilde kaplama ünitesindeki $3 \mathrm{MB}$ plazma tabancası ile gerçekleştirilmiştir. Plazma püskürtme tekniğine ait kaplama parametreleri Tablo 2'de verilmiştir.

Tablo 1. Alüminyum alaşımı alt malzemenin kimyasal bileşimi

\begin{tabular}{|c|c|c|c|c|c|}
\hline \multicolumn{7}{|c|}{ A ğırlık Element (\%) } \\
\hline $\mathrm{Al}$ & $\mathrm{Si}$ & $\mathrm{Ni}$ & $\mathrm{Cu}$ & $\mathrm{Mg}$ & $\mathrm{Fe}$ \\
\hline Kalan & 12.6 & 1.96 & 0.88 & 0.60 & 0.5 \\
\hline
\end{tabular}

Tablo 2. $\mathrm{Al}_{2} \mathrm{O}_{3}+\% 13 \mathrm{TiO}_{2}$ ve $\mathrm{Cr}_{2} \mathrm{O}_{3} / \mathrm{Al}_{2} \mathrm{O}_{3}$ tozlarına ait plazma püskürtme parametreleri

\begin{tabular}{|c|c|c|}
\hline Parametreler & $\begin{array}{c}\mathrm{Al}_{2} \mathrm{O}_{3}+\% 13 \mathrm{TiO}_{2} \\
\text { Kaplama }\end{array}$ & $\begin{array}{c}\mathrm{Cr}_{2} \mathrm{O}_{3} \text { ve } \\
\mathrm{Cr}_{2} \mathrm{O}_{3}+\% 25 \mathrm{Al}_{2} \mathrm{O}_{3} \\
\text { Kaplama }\end{array}$ \\
\hline Plazma Tabancas1 & $3 \mathrm{MB}$ & $3 \mathrm{MB}$ \\
\hline Akım (A) & 500 & 500 \\
\hline Gerilim (V) & 70 & 70 \\
\hline Birinci gaz-Ar (1/min) & 80 & 80 \\
\hline İkinci gaz- $\mathrm{H}_{2}(1 / \mathrm{min})$ & 25 & 15 \\
\hline Püskürtme mesafesi (mm) & $100-125$ & $64-90$ \\
\hline Nozul çapı (mm) & 7.6 & 7.6 \\
\hline
\end{tabular}




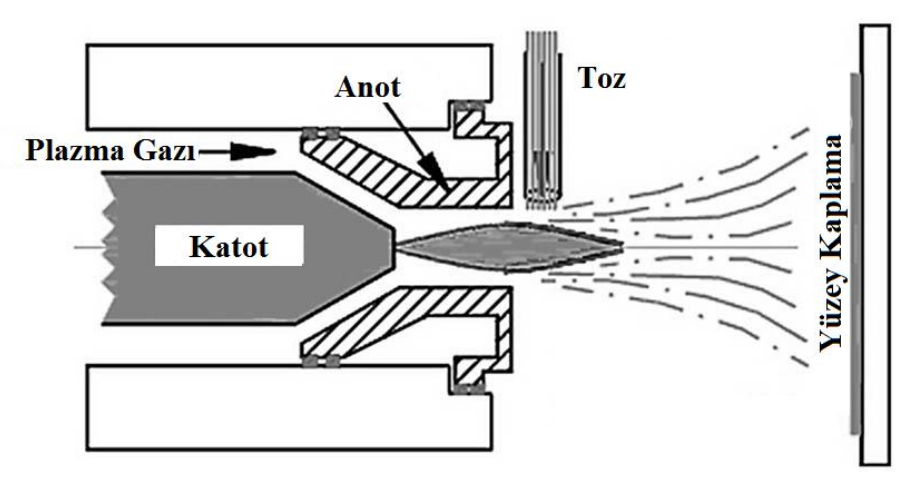

Şekil 1. Plazma Püskürtme Kaplama Sistemi

Yüzeyi kaplanan numunelerden, kaplama yönüne dik kesitte mikroyapı numunesi çıkarılmıştır. Kesilen numune yüzeylerin yüzeyleri 600, 800, 1000 ve 1200 mesh'lik zımparalar kullanılarak düzeltilmiş ve daha sonra elmas pasta kullanılarak çuhayla parlatılmıştır. Dağlama işlemi uygulamadan mikroyapı incelemesi için hazırlanmış numunelerin optik mikroskopta fotoğrafları çekilmiştir. Yüzey pürüzlülük ölçümleri Mitutoyo Surftest-211 marka cihazda aynı yüzeyin farklı bölgelerinden ölçümler tekrarlanıp aritmetik ortalaması hesaplanarak, Ra cinsinden tespit edilmiştir.

\section{Deneysel Sonuçlar}

\subsection{Kaplamaların Mikroyapı İncelemesi}

Plazma püskürtme kaplama tekniği ile gerçekleştirilen $\mathrm{Al}_{2} \mathrm{O}_{3}+\% 13 \mathrm{TiO}_{2}, \mathrm{Cr}_{2} \mathrm{O}_{3}$ ve $\mathrm{Cr}_{2} \mathrm{O}_{3}+\% 25 \mathrm{Al}_{2} \mathrm{O}_{3}$ toz kaplamaların optik mikroyapı resimleri Şekil 2'de verilmiştir. Kaplanan numunelerin mikroyapı resimleri incelendiğinde, kaplama tabakaların tümünde gözenekli bir yapının oluştuğu görülmektedir. Numunelerde 200-300 $\mu \mathrm{m}$ civarında değişen tabaka kalınlıkları elde edilmiştir.

Kaplama tabakaları incelendiğinde, $\mathrm{Al}_{2} \mathrm{O}_{3}+\% 13 \mathrm{TiO}_{2}$ tozu ile kaplanan numunede lamelli bir yapının oluştuğu görülmektedir. Literatür çalışmalarında [10,11], optik mikroyapı resimlerinde koyu gri renkteki lamelli bölgelerin $\mathrm{TiO}_{2}$, açı renkteki bölgelerin ise $\mathrm{Al}_{2} \mathrm{O}_{3}$ bileşiklerinden oluştuğu gösterilmektedir. $\mathrm{Al}_{2} \mathrm{O}_{3}+\% 13 \mathrm{TiO}_{2}$ tozu ile kaplanan numunenin kaplama tabakasından alınan SEM, EDS ve XRD analizleri Şekil 3'te verilmiştir. Kaplama tabakasında lamelli bölgeden 1 nolu noktadan alınan EDS analizinde Ti \%54.15, O \%43.56 ve Al \%2.28 değerlerinde tespit edilmiştir. Bu değerler Şekil 3d'de verilen XRD analizinde de gösterildiği gibi lamelli bölgenin $\mathrm{TiO}_{2}$ bileşiğinden oluştuğunu doğrulamaktadır. Diğer yandan, optik mikroyapı görüntüsünde koyu gri renkte görünen ve SEM fotoğrafinda 2 nolu bölgeden alınan EDS analizinde Al \%40.13, O \%55.98 ve Ti \%3.89 değerlerinde tespit edilmiştir. $\mathrm{Bu}$ değerler Şekil 3d'de verilen XRD analizinde de gösterildiği gibi 2 nolu bölgenin $\mathrm{Al}_{2} \mathrm{O}_{3}$ bileşiğinden oluştuğunu doğrulamaktadır. Tespit edilen bileşikler, literatürle uyum sağlamaktadır. 

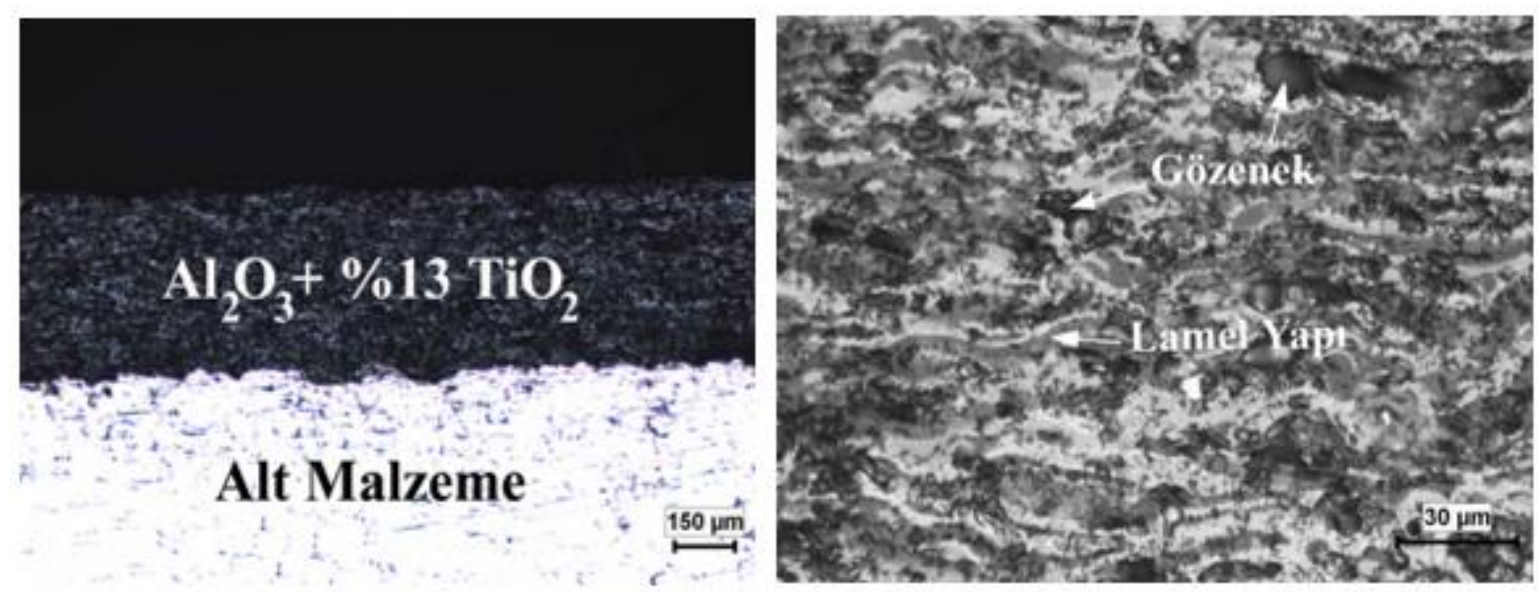

(a)
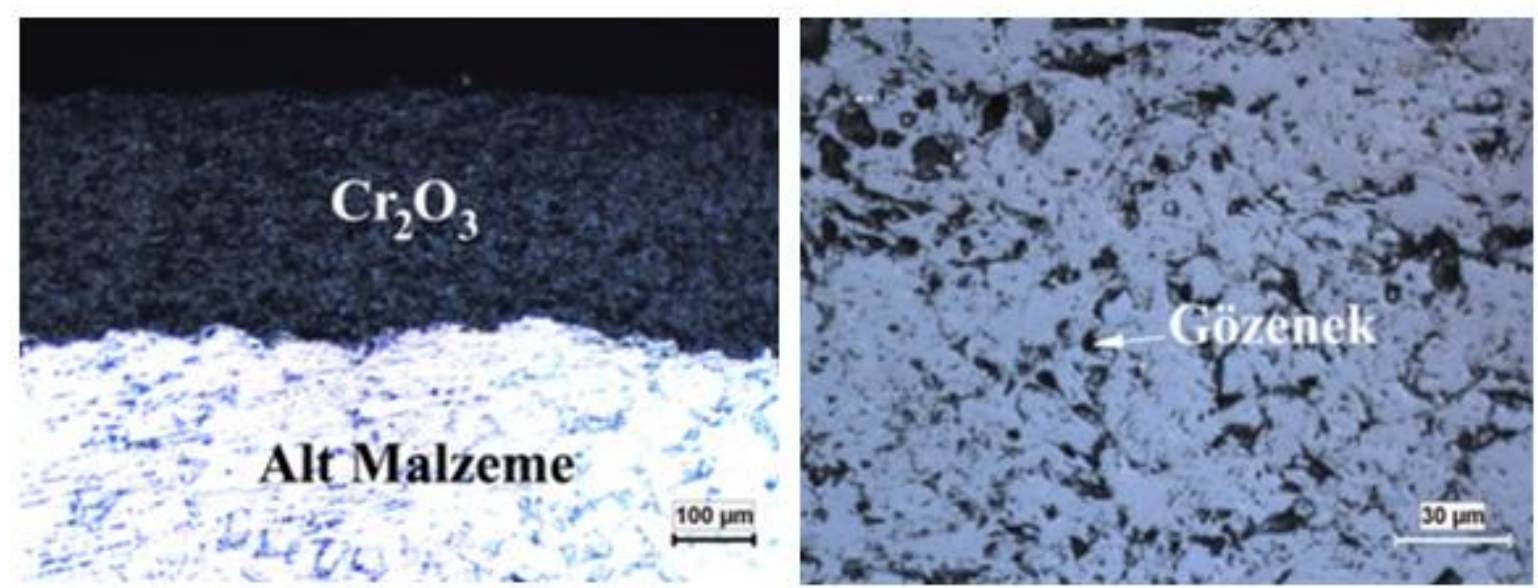

(b)
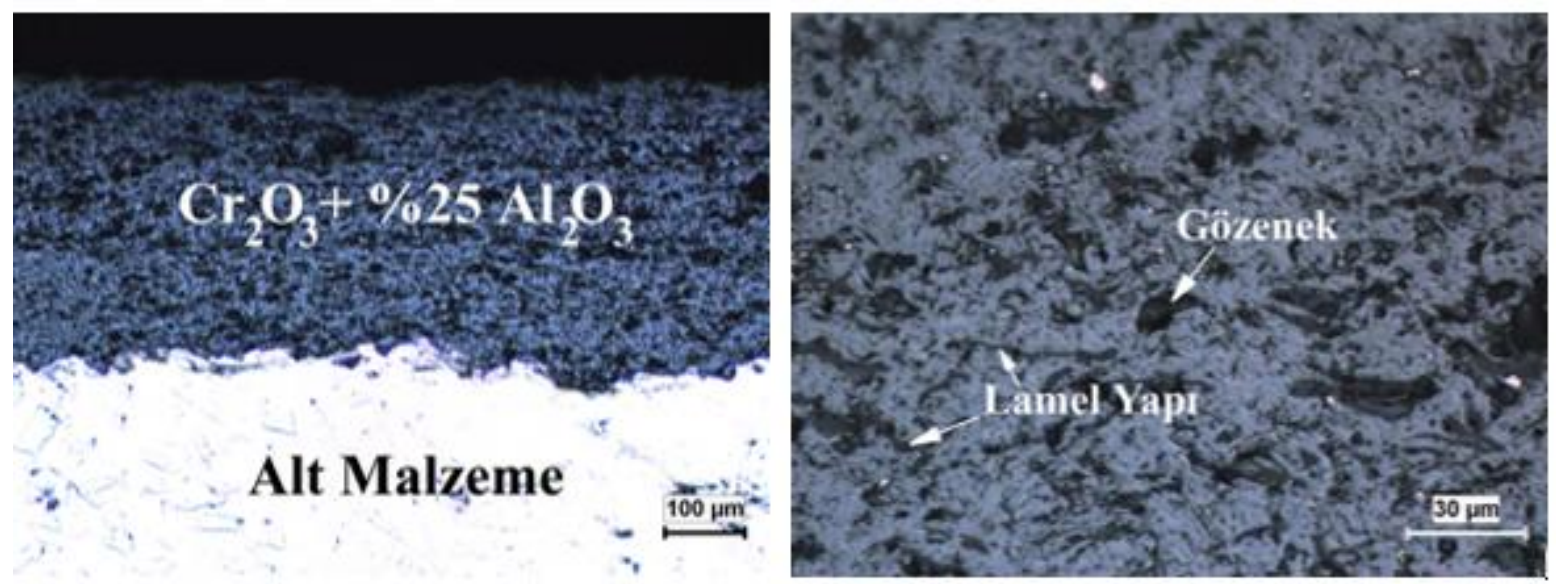

(c)

Şekil 2. a) $\mathrm{Al}_{2} \mathrm{O}_{3}+\% 13 \mathrm{TiO}_{2}$, b) $\mathrm{Cr}_{2} \mathrm{O}_{3}$ ve c) $\mathrm{Cr}_{2} \mathrm{O}_{3}+\% 25 \mathrm{Al}_{2} \mathrm{O}_{3}$ tozlar1 ile kaplanan numunelerin optik mikroyapı resimleri 


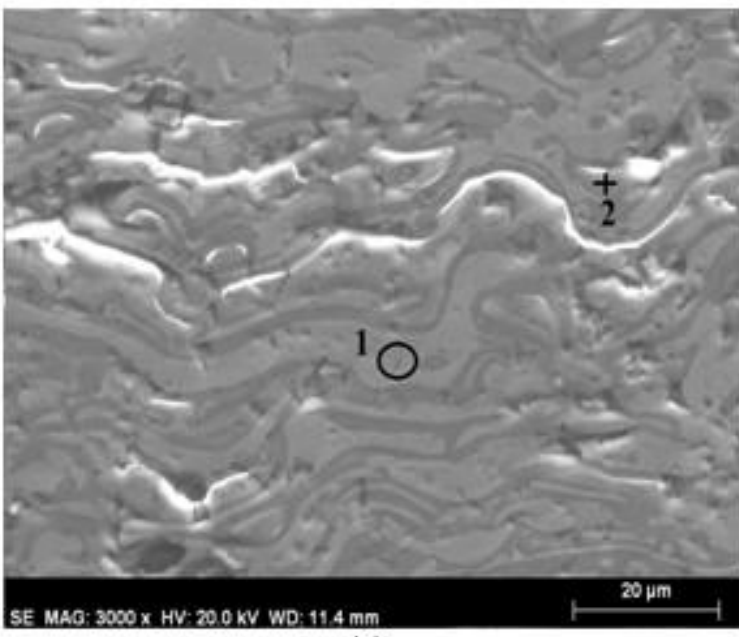

(a)

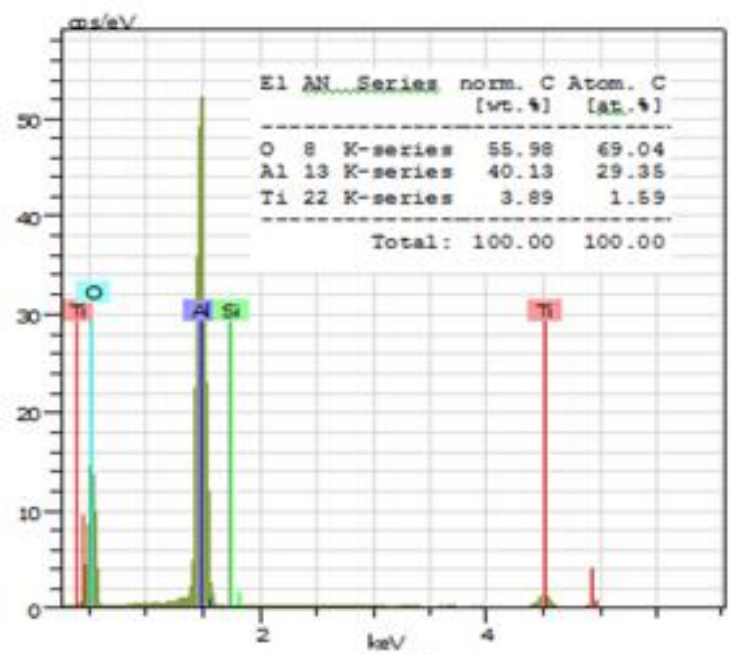

(c)

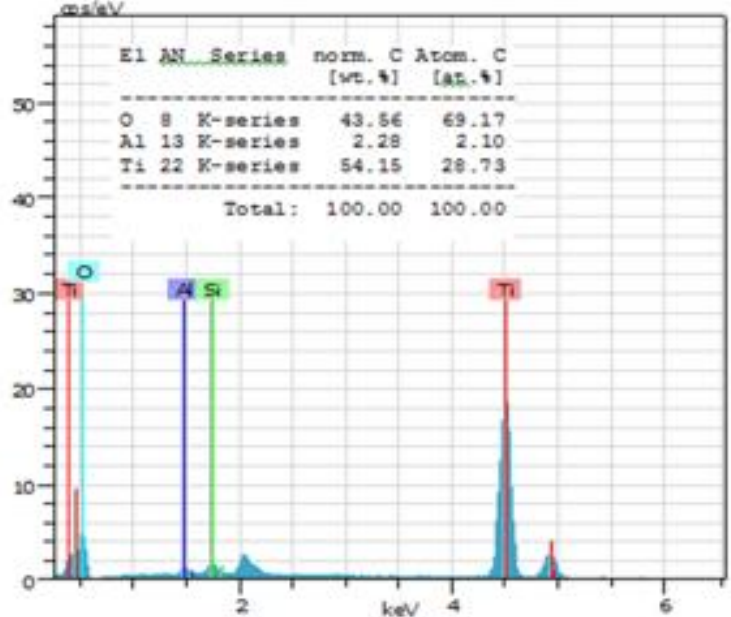

(b)

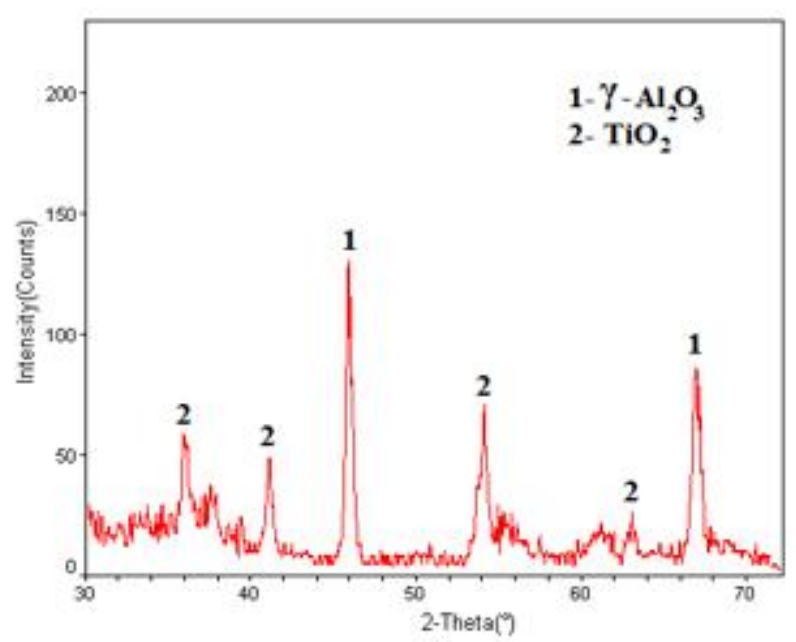

(d)

Şekil 3. $\mathrm{Al}_{2} \mathrm{O}_{3}+\% 13 \mathrm{TiO}_{2}$ tozu ile kaplanan numunenin, a)SEM fotoğrafi, b) 1 nolu EDS analizi, c) 2 nolu EDS analizi ve d) XRD analizi

$\mathrm{Cr}_{2} \mathrm{O}_{3}$ tozu ile kaplanan numune incelendiğinde, kaplama tabakasında gözenek miktarının az olduğu görülmektedir (Şekil 2). $\mathrm{Cr}_{2} \mathrm{O}_{3}$ içerisine $\% 25 \mathrm{Al}_{2} \mathrm{O}_{3}$ ilavesi ile gerçekleştirilen kaplamalarda ise gözenek miktarının $\mathrm{Al}_{2} \mathrm{O}_{3}$ ilavesi ile arttığı ve lamelli yapının oluştuğu görülmektedir. $\mathrm{Cr}_{2} \mathrm{O}_{3}+\% 25$ $\mathrm{Al}_{2} \mathrm{O}_{3}$ tozu ile kaplanan numunenin kaplama tabakasından alınan SEM, EDS ve XRD analizleri Şekil 4 'te verilmiştir. Kaplama tabakasında 3 nolu bölgeden alınan EDS analizinde Cr \%61.96, O \%37.72 ve Al \%0.32 değerlerinde tespit edilmiştir. Bu değerler Şekil 4d'de verilen XRD analizinde de gösterildiği gibi bölgenin $\alpha-\mathrm{Cr}_{2} \mathrm{O}_{3} / \mathrm{Cr}_{2} \mathrm{O}_{3}$ bileşiğinden oluştuğunu doğrulamaktadır. Diğer yandan, optik mikroyapı görüntüsünde koyu gri renkte görünen ve SEM fotoğrafında lamelli yapının üzerindeki 4 nolu noktadan alınan EDS analizinde $\mathrm{Al} \% 41.52$, O \%56.95 ve $\mathrm{Cr} \% 1.53$ değerlerinde tespit edilmiştir. Bu değerler Şekil 3d'de verilen XRD analizinde gösterildiği gibi 4 nolu bölgenin $\mathrm{Al}_{2} \mathrm{O}_{3}$ bileşiğinden oluştuğunu doğrulamaktadır. 


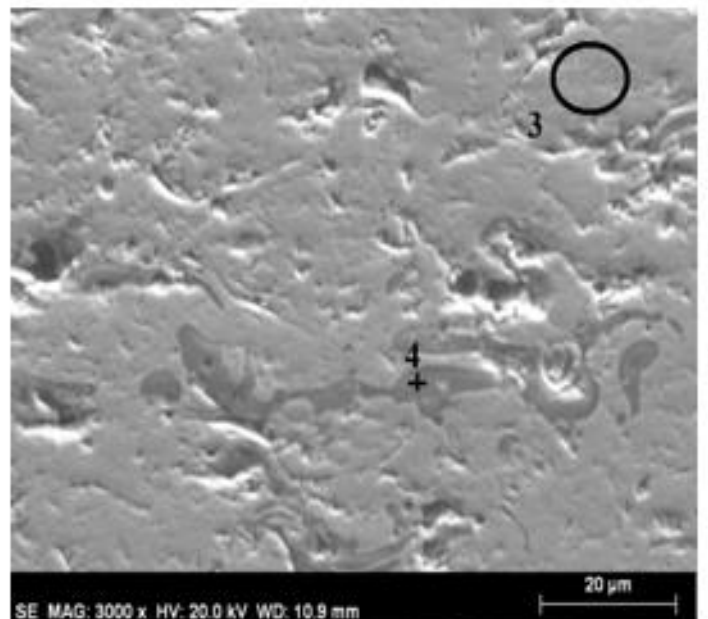

(a)

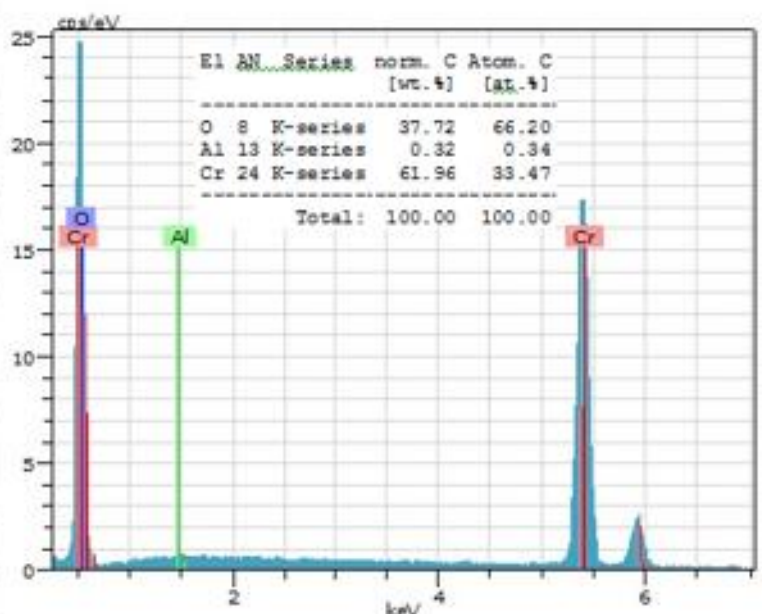

(b)

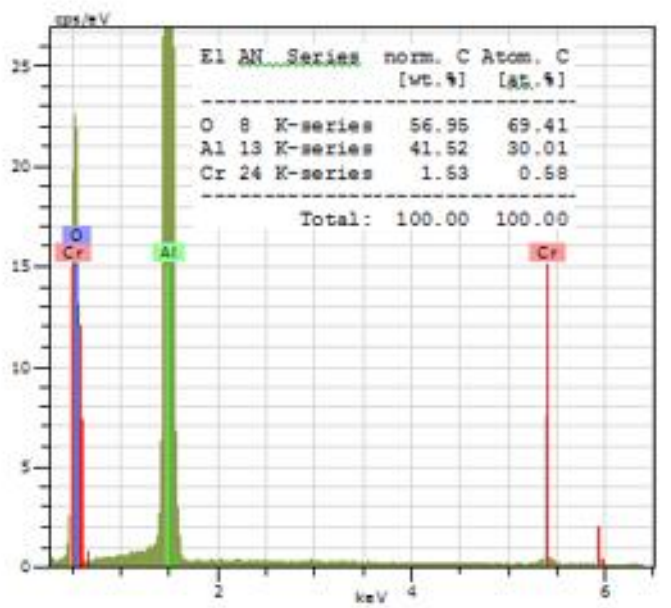

(c)

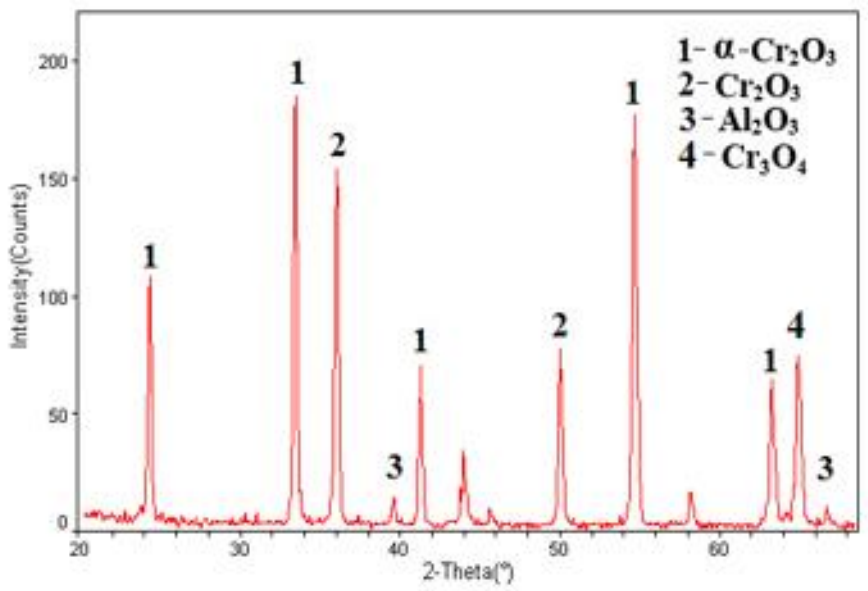

(d)

Şekil 4. $\mathrm{Cr}_{2} \mathrm{O}_{3}+\% 25 \mathrm{Al}_{2} \mathrm{O}_{3}$ tozu ile kaplanan numunenin, a)SEM fotoğrafi, b) 3 nolu EDS analizi, c) 4 nolu EDS analizi ve d) XRD analizi

\subsection{Kaplamaların Yüzey Pürüzlülüğü}

Numunelerin kaplama öncesi, yüzey pürüzlendirme işlemi sonrası ve kaplama sonrası yüzey pürüzlülük değerleri ölçülmüştür. Ölçümlerde, kaplama işlemi uygulanmamış numunede $3.742 \mu \mathrm{m}$, yüzeyi sadece pürüzlendirilmiş numunede ise $4.521 \mu \mathrm{m}$ yüzey pürüzlülük değerleri tespit edilmiştir. Numune yüzeyine yapılan kaplamalar ile farklı yüzey pürüzlülük değerleri tespit edilmiştir. $\mathrm{Al}_{2} \mathrm{O}_{3}+\% 13 \mathrm{TiO}_{2}$ tozu ile kaplanan numunede yüzeyinde 5,398 $\mu \mathrm{m}, \mathrm{Cr}_{2} \mathrm{O}_{3}$ tozu ile kaplanan numunede yüzeyinde $6.540 \mu \mathrm{m}$ ve $\mathrm{Cr}_{2} \mathrm{O}_{3}+\% 25 \mathrm{Al}_{2} \mathrm{O}_{3}$ tozu ile kaplanan numune yüzeyinde $4.121 \mu \mathrm{m}$ pürüzlülük değeri tespit edilmiştir. Kaplanan numunelerde en düşük yüzey pürüzlülük değeri $\mathrm{Cr}_{2} \mathrm{O}_{3}+\% 25 \mathrm{Al}_{2} \mathrm{O}_{3}$ tozu ile kaplanan numunede tespit edilmiştir. $\mathrm{Cr}_{2} \mathrm{O}_{3}$ içerisine ilave edilen $\mathrm{Al}_{2} \mathrm{O}_{3}$, yüzey pürüzlülük değerinin düşmesine neden olmuştur. 


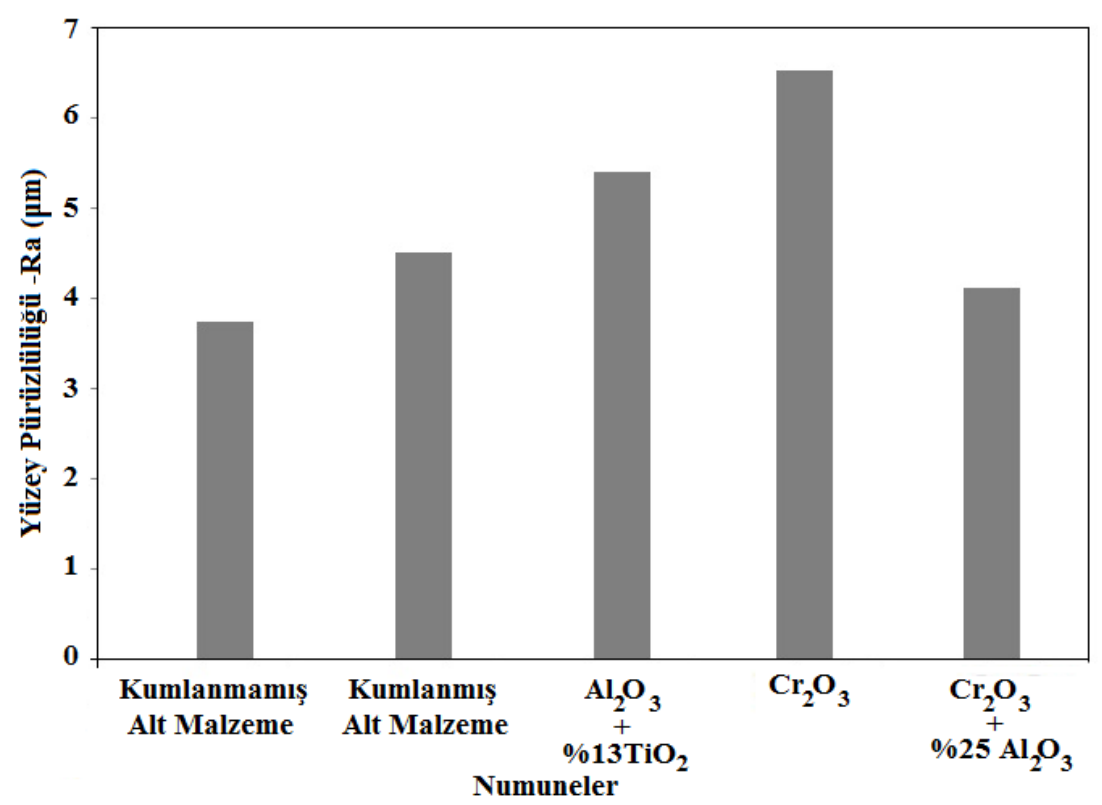

Şekil 5. Kumlanmamış ve kumlanmış alt malzeme ile kaplanan numunelerin yüzey pürüzlülük değerleri

\section{Sonuç}

1. Alüminyum alaşımı yüzeyine, plazma püskürtme tekniği kullanılarak $\mathrm{Al}_{2} \mathrm{O}_{3}+\% 13 \mathrm{TiO}_{2}, \mathrm{Cr}_{2} \mathrm{O}_{3}$ ve $\mathrm{Cr}_{2} \mathrm{O}_{3}+\% 25 \mathrm{Al}_{2} \mathrm{O}_{3}$ tozları kaplanabilmektedir.

2. Plazma püskürtme yöntemi ile gerçekleştirilen kaplamaların tümünde gözenekli bir yapı elde edilmiştir. En düşük gözeneklilik miktarı $\mathrm{Cr}_{2} \mathrm{O}_{3}$ tozu ile kaplanan numunede tespit edilmiştir.

3. En yüksek yüzey pürüzlülüğü $6.540 \mu \mathrm{m}$ değeri ile $\mathrm{Cr}_{2} \mathrm{O}_{3}$ tozu ile kaplanan numunede, en düşük yüzey pürüzlülügü ise $4.121 \mu \mathrm{m}$ değeri ile $\mathrm{Cr}_{2} \mathrm{O}_{3}+\% 25 \mathrm{Al}_{2} \mathrm{O}_{3}$ tozu ile kaplanan numunede tespit edilmiştir.

\section{Teșekkür}

Bu çalışmanın gerçekleşmesinde BEBAP-2014.15 no'lu proje ile maddi destek sağlayan Bitlis Eren Üniversitesi Bilimsel Araştırma Projeler Birimi'ne ve numunelerin analizlere hazırlanmasında faydalanılan Bitlis Eren Üniversitesi Bilim ve Teknoloji Araştırma ve uygulama Merkezine sonsuz teşekkürlerimizi sunarız.

\section{Kaynaklar}

1. Özel S, 2013. Yüzey Kaplama İşlemlerinde Kullanılan Isıl Püskürtme Yöntemleri, Bitlis Eren Üniversitesi Fen Bilimleri Dergisi, 2 (1): 88-97.

2. Barbezat G, 2005. Advanced Thermal Spray Technology and Coating for Lightweight Engine Blocks for the Automotive Industry, Surface \& Coatings Technology, 200: 1990-1993.

3. Lin BT, Jean MD, Chou JH, 2007. Using Response Surface Methodology for Optimizing Deposited Partially Stabilized Zirconia in Plasma Spraying, Applied Surface Science, 253: 32543262. 
4. Kıratlı N, Yetgin SH, Çöğür T, 2009. Toz Alev Püskürtme Yöntemi Kullanılarak Kaplanan Alüminyum Alaşımının Aşınma ve Sertlik Davranışlarının İncelenmesi, Pamukkale Üniversitesi Mühendislik Bilimleri Dergisi, 15 (3): 441-446.

5. Sarı NY, Yılmaz M, 2005. Ni-Esaslı Kaplamaların Abrazif+Erozif Aşınma Direncine Isı1 Püskürtme Yönteminin ve WC İlavesinin Etkisi, Mühendis ve Makine, 46 (541): 14-20.

6. Evcin A, Kepekçi DB, Barut İ, 2009. Hidroksiapatit Tozlarının Plazma Sprey Yöntemiyle Paslanmaz Çelik Üzerine Kaplanması, 5. Uluslararası İleri Teknolojiler Sempozyumu (IATS'09), 1077-1081, 13-15 Mayıs, Karabük, Türkiye.

7. Wang D, Tian Z, Wang S, Shen L, Liu Z, 2014. Microstructural characterization of $\mathrm{Al}_{2} \mathrm{O}_{3}-$ 13 wt. $\% \mathrm{TiO}_{2}$ ceramic coatings prepared by squash presetting laser cladding on $\mathrm{GH} 4169$ superalloy, Surface and Coatings Technology, 254: 195-201.

8. Wang Y, Jiang S, Wang M, Wang S, Xiao TD, Strutt PR, 2000. Abrasive wear characteristics of plasma sprayed nanostructured aluminartitania coatings, Wear, 237: 176-185.

9. Shao F, Yang K, Zhao H, Liu C, Wang L, Tao S, 2015. Effects of inorganic sealant and brief heat treatments on corrosion behaviour of plasma sprayed $\mathrm{Cr}_{2} \mathrm{O}_{3}-\mathrm{Al}_{2} \mathrm{O}_{3}$ composite ceramic coatings, Surface and Coatings Technology, 276: 8-15.

10. Fervel V, Normand B, Coddet C, 1999. Tribological behaviour of plasma sprayed $\mathrm{Al}_{2} \mathrm{O}_{3}$ based cermet coatings, Wear, 230: 70-77.

11. Lina X, Zenga Y, Leeb S W, Ding C, 2004. Characterization of alumina-3 wt \% titania coating prepared by plasma spraying of nanostructured powders, Journal of the European Ceramic Society, 24: 627-634.

Geliş Tarihi: 06/11/2015

Kabul Tarihi: 27/11/2015 